\title{
A GESTÃO DOS RESÍDUOS SÓLIDOS RECICLÁVEIS EM PRESIDENTE PRUDENTE - SÃO PAULO - BRASIL
}

\author{
Fernando Sérgio Okimoto ${ }^{1}$
}

\author{
Estela Violin de Melo ${ }^{2}$
}

Maíra Tudine Roque ${ }^{3}$

\begin{abstract}
RESUMO
Este trabalho apresenta, para o Município de Presidente Prudente/SP, uma proposta integradora da gestão de resíduos sólidos recicláveis com as responsabilidades sociais, ambientais e econômicas de toda a comunidade através do CISSA - Centro de Integração Social e Sustentabilidade Ambiental. Trata-se de um equipamento urbano em que acomodará as atividades de gestão dos resíduos recicláveis, a organização e capacitação dos catadores destes resíduos e a educação ambiental da comunidade local. Foram realizados levantamentos da situação atual através de trabalhos de campos e dos dados fornecidos pela gestão municipal. A partir de então, foi elaborada uma proposta de implementação de um CISSA na antiga fábrica de tubos e de asfalto da empresa que atualmente gerencia a coleta de resíduos no Município. Assim, a proposta ora apresentada pretende que o saneamento ambiental seja mais eficiente e que o trabalho dos catadores seja menos precário e a situação socioeconômica seja menos frágil.
\end{abstract}

PALAVRAS-CHAVE: Resíduos sólidos. Reciclagem. Gestão de RSU.

\section{THE MANAGEMENT OF SOLID WASTE IN RECYCLABLES PRESIDENTE PRUDENTE - SÃO PAULO - BRAZIL}

\section{ABSTRACT}

\footnotetext{
${ }^{1}$ Doutor em Engenharia Civil, Professor da Universidade Estadual Paulista “Júlio de Mesquita Filho" Faculdade de Ciências e Tecnologia - Campus de Presidente Prudente, Curso de Arquitetura e Urbanismo,okimotofs@fct.unesp.br.

${ }^{2}$ Graduanda do curso de Arquitetura e Urbanismo da UNESP - Campus de Presidente Prudente, bolsa de Extensão Universitária - 2014. estela.violin@hotmail.com.

${ }^{3}$ Graduanda do curso de Arquitetura e Urbanismo da UNESP - Campus de Presidente Prudente, bolsa de Extensão Universitária - 2013 e 2014. mairatudine@gmail.com.
} 
This paper presents an integrative proposal of recyclable solid waste management for the city of Presidente Prudente/SP, with social, environmental and economic responsibilities of the entire community through CISSA Centre of Social Integration and Environmental Sustainability. It is an urban facility that will accommodate the activities of management of recyclable waste, the organization and training of these waste pickers and environmental education to the local community. Surveys the current situation through field work and the municipality provided the data available. Thereafter, a proposal for implementing a CISSA in Prudenco factory that currently manages waste collection in the city was prepared. Thus, the present proposal intends that the environmental sanitation is more efficient and that the work of the collectors is less precarious and the socioeconomic situation becomes is less fragile.

\section{GESTIÓN DE RESIDUOS SÓLIDOS EN RECYCLABLES PRESIDENTE PRUDENTE - SÃO PAULO - BRASIL}

\section{RESUMEN}

Este trabajo presenta, para la ciudad de Presidente Prudente / SP, propuesta integradora de la gestión de residuos sólidos reciclables con responsabilidades sociales, ambientales y económicos de toda la comunidad a través CISSA - Centro de Integración Social y la sostenibilidad ambiental. Es una instalación urbana que se acomoda a las actividades de gestión de residuos reciclables, la organización y la formación de estos recolectores de residuos y educación ambiental de la comunidad local. Las encuestas de la situación actual se llevaron a cabo a través de trabajo de campo y los datos suministrados por la administración municipal. A partir de entonces elaboró una propuesta para la implementación de un CISSA la antigua compañía de molino de bolas y el asfalto que en la actualidad gestiona la recogida de residuos en la ciudad. Por lo tanto, la presente propuesta pretende que el saneamiento ambiental es más eficiente y que el trabajo de los colectores es menos precaria y el nivel socioeconómico son menos frágiles.

PALABRAS-CLAVE Los residuos sólidos. Reciclaje. Manejo de los RSM.

\section{INTRODUÇÃO}

\subsection{Generalidade}

Atualmente a COOPPRUDENTE e a COOPERLIX (Cooperativa de trabalho, produção e reciclagem de Presidente Prudente) são responsáveis pela realização das atividades de coleta e triagem de material reciclável de Presidente Prudente.

\subsection{Justificativa}


A elaboração de propostas para melhoria do galpão de triagem é de suma importância tanto para o Ministério do Meio Ambiente como para a Prefeitura local, que buscam benefícios para a cidade, para que ocorra uma efetiva coleta seletiva e reciclagem, garantindo renda aos catadores e benefícios socioambientais a cidade.

\subsection{Objetivo do Trabalho}

O CISSA, Centro de Integração Social e Sustentabilidade Ambiental, tem o intuito de organizar as atividades administrativas relacionadas ao galpão de reciclagem e os cuidados próprios com os resíduos, no âmbito da coleta, triagem e comercialização dos materiais recicláveis. O objetivo deste trabalho é apresentar a situação atual da gestão dos resíduos sólidos recicláveis em Presidente Prudente e propor melhoria do galpão existente e a criação de um novo CISSA. Objetivou-se, também, implantar espaços para a educação ambiental dos envolvidos no processo de reciclagem e também para população. 


\subsection{Metodologia}

A metodologia para obtenção de dados sobre o atual galpão de reciclagem foi através de levantamento de dados da área analisada, por meio de fotos, e aquisição de materiais (mapas e projetos) pela prefeitura local.

Após tal avaliação, foi elaborada uma proposta de melhorias na infraestrutura existente e na organização logística da coleta seletiva.

\section{DESENVOLVIMENTO}

\subsection{Análises do local}

$\mathrm{Na}$ área em análise, isto é, na área anteriormente destinada à Usina de Asfalto a Frio de Presidente Prudente e Fábricas de Tubos de Concreto da P.M.P.P. Prefeitura Municipal de Presidente Prudente estão previstos diferentes usos: há uma parte destinada ao funcionamento administrativo da Prudenco (empresa associada à prefeitura), outra destinada a fabrica de asfalto que hoje se encontra desativada e a área de triagem dos resíduos sólidos, ,realizada pela CoopPrudente. E também de suma importância a área dos Lagos, como pode ser visto na imagem abaixo. 
FIGURA 1. Planta de cobertura com divisão dos patamares e usos de cada área.

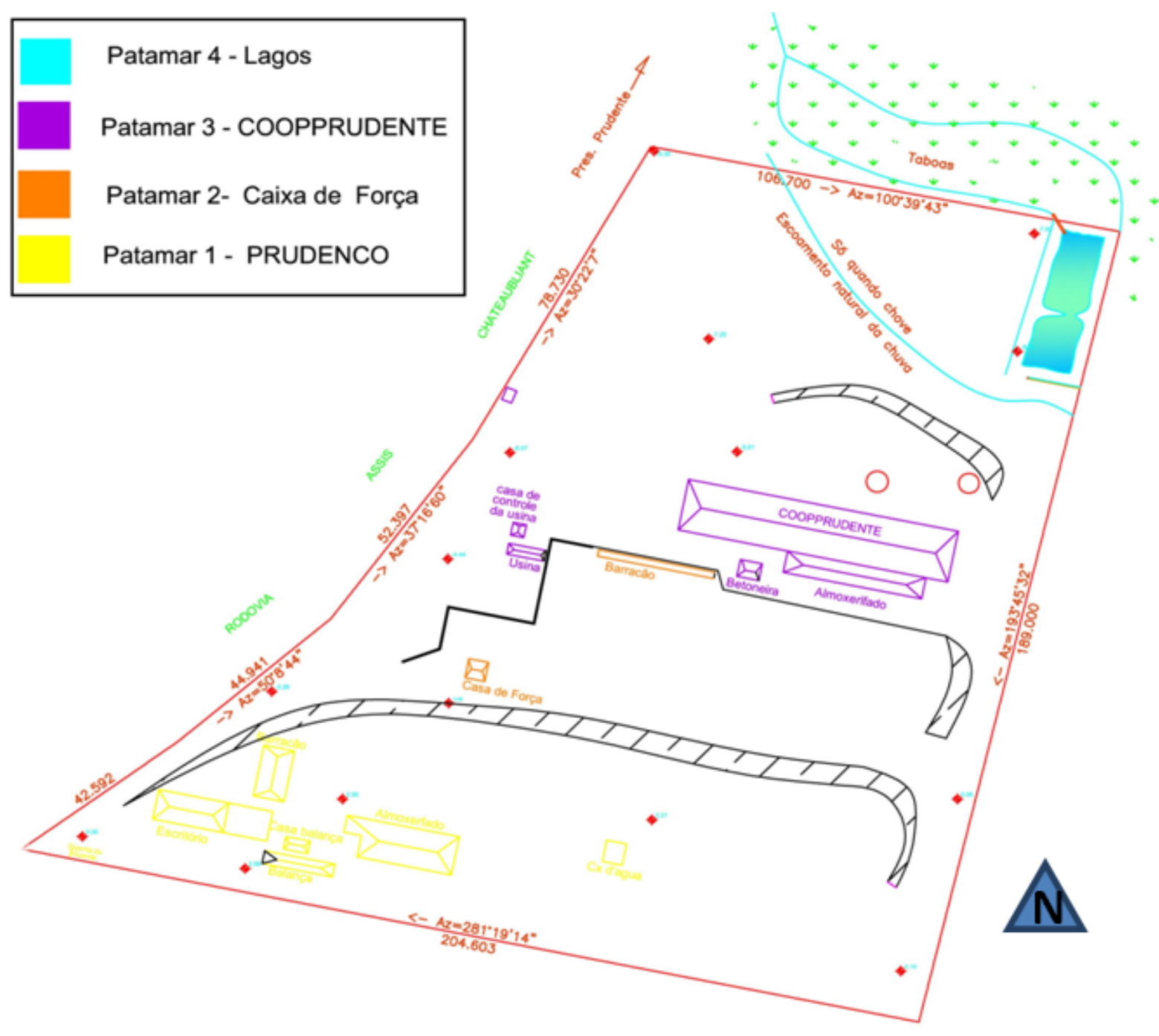

Fonte: PROEX, 2013.

Essas quatro áreas se separam pela topografia, em declive para o norte respectivamente, como mostra a planta acima.

No primeiro e mais elevado patamar, se encontra uma edificação com uma sala de escritório, um banheiro, uma cozinha, e um almoxarifado além da balança dos resíduos. 
FIGURA 2. (a) Fotografia da sala administrativa; (b) Fotografia da balança de pesagem dos resíduos.
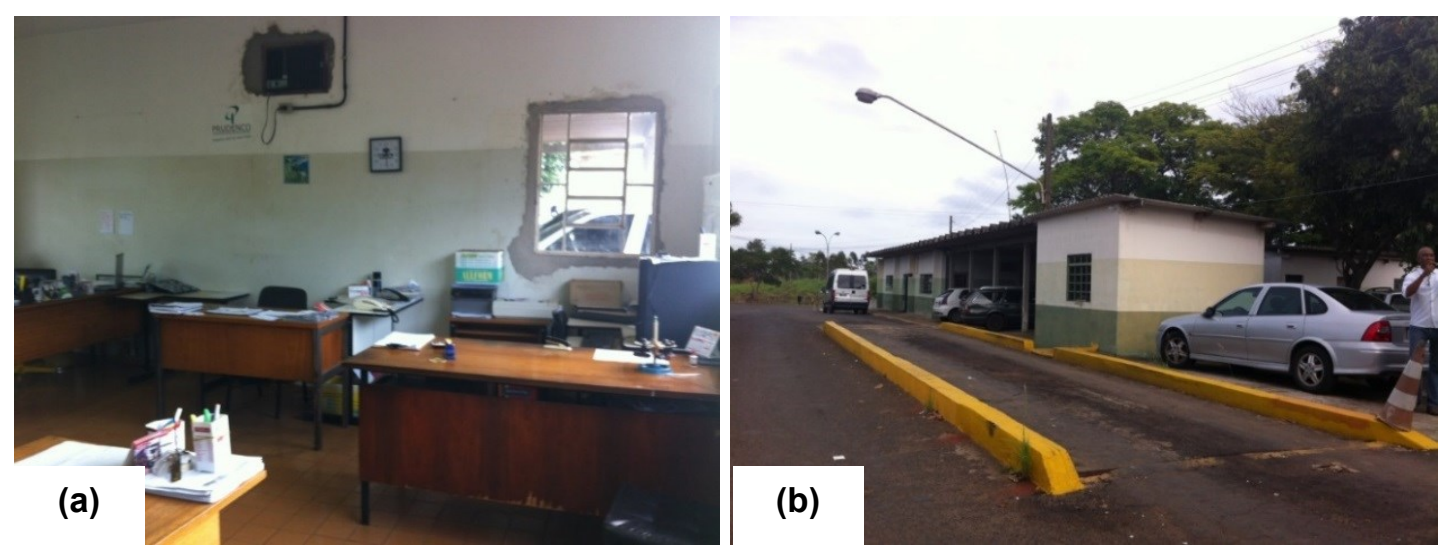

Fonte: PROEX, 2013.

Com desnível cerca de 5 metros, o segundo patamar se dispõem da casa de força e uma cobertura que também se encontra sem uso especifico.

O terceiro patamar também se encontra a um desnível de 5 metros em relação ao segundo, e nessa área se dá todo o funcionamento da atividade de triagem de materiais recicláveis da CoopPrudente e de outro grupo que trabalha com o excesso o qual a cooperativa não consegue triar. Além da antiga fábrica de asfalto e tubos da P.M.P.P. 
FIGURA 3. (a) Fotografia do atual galpão de reciclagem; (b) Fotografia dos resíduos aguardando triagem.

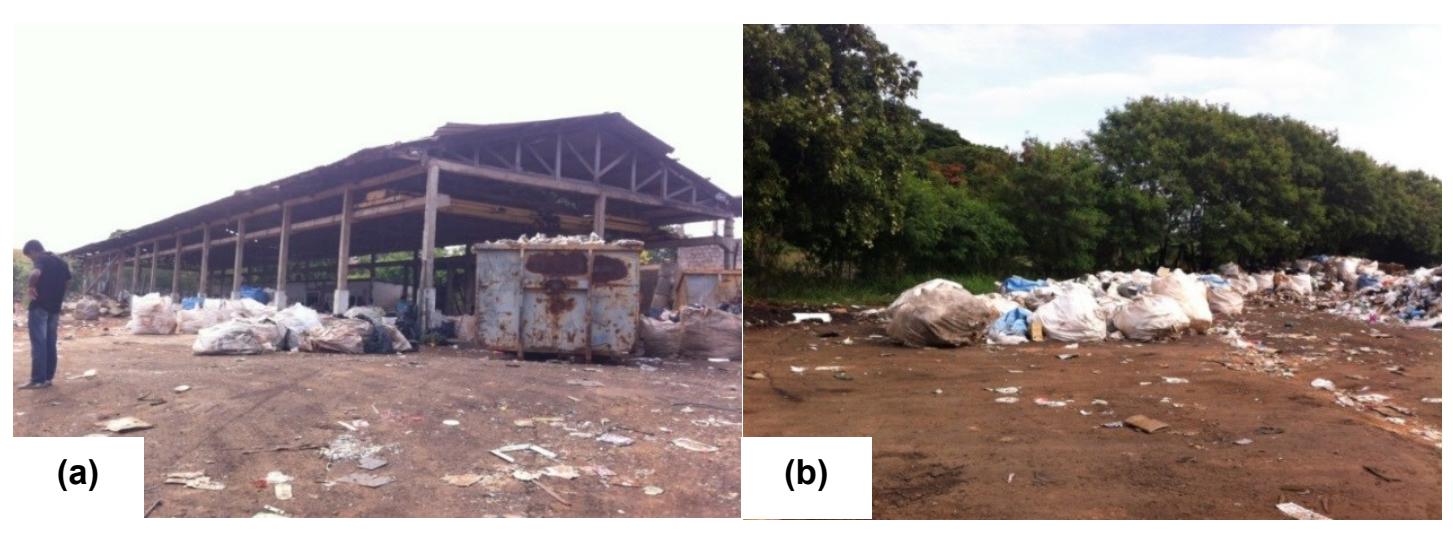

Fonte: PROEX, 2013.

FIGURA 4. (a) Fotografia da antiga fábrica de asfalto; (b) Tanque de armazenamento.
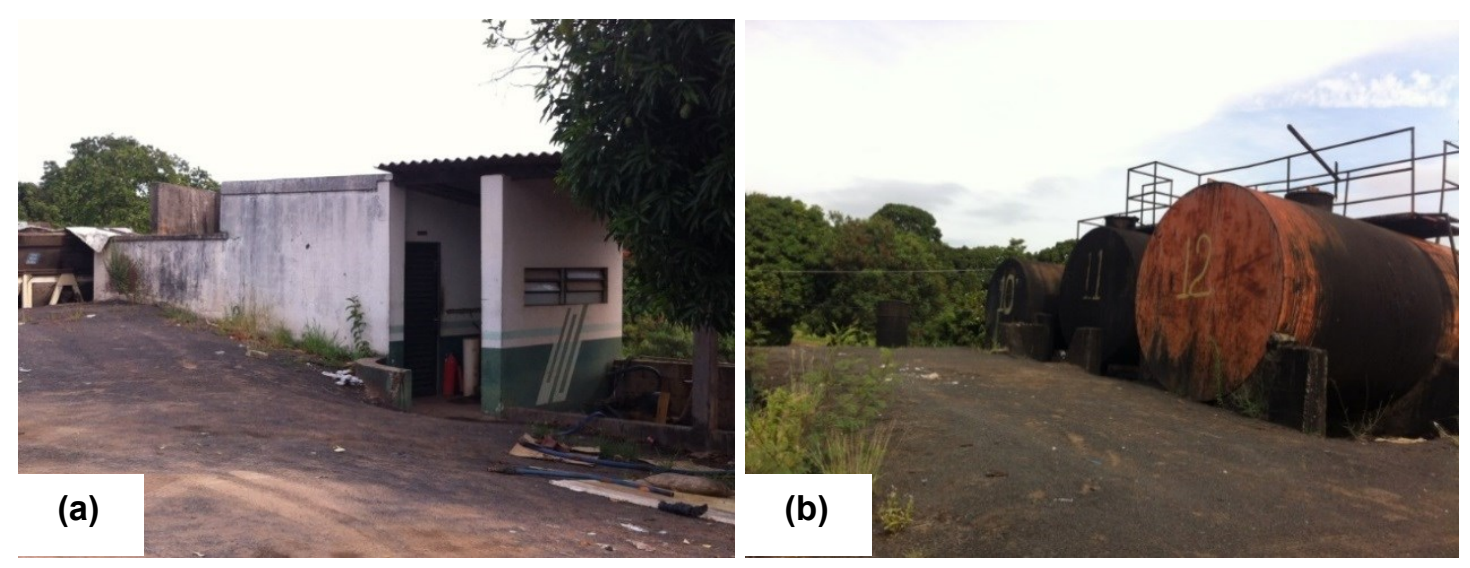

Fonte: PROEX, 2013.

No quarto e último patamar, têm-se dois lagos na área do taboal, e em seu entorno há uma área de inundação (quando chove). Neste patamar há um uso como depósito de veículos inutilizados. 
FIGURA 5. (a) Fotografia dos Lagos; (b) Depósito de veículos.

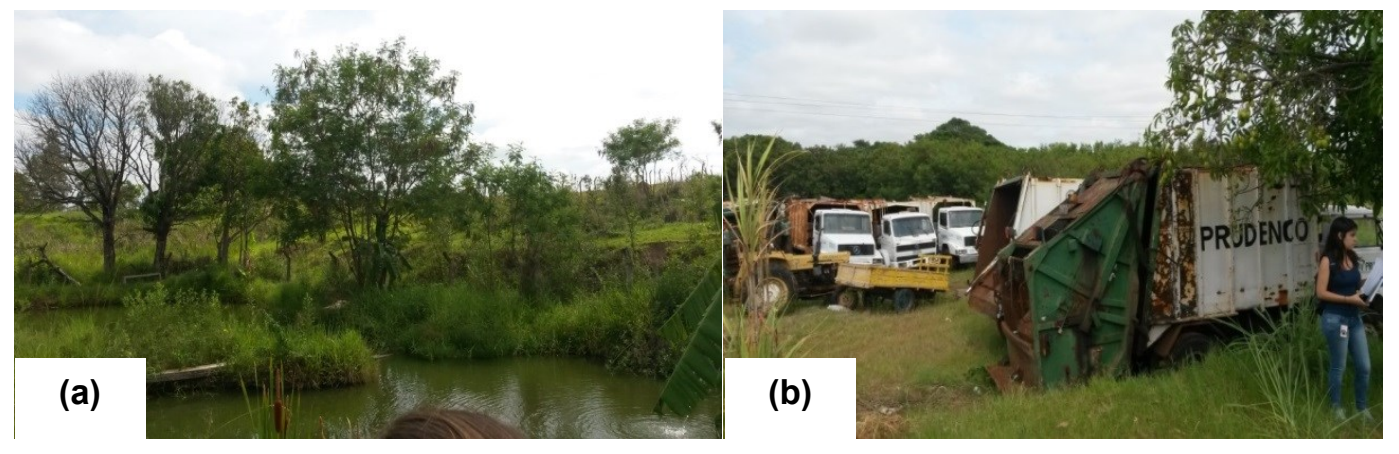

Fonte: PROEX, 2013.

No local, se recebe diversos tipos de materiais, desde os mais convencionais para reciclagem, os de maior valor comercial o alumínio e o cobre, como também aqueles de pouco ou nenhum valor comercial como baldes e bacias, eletrônicos e plásticos metalizados. A triagem seleciona apenas os de interesse comercial e em bom estado de conservação para elevar o valor de venda, comprometendo o adequado saneamento ambiental do serviço que prestam.

A eficiência das atividades da cooperativa está bastante comprometida devida uma série de fatores como: - a falta de maquinários adequados (prensas, esteiras, baias,) para que haja uma qualidade no trabalho realizado; - ausência de um fluxo programado para cada atividade; - a incompatibilidade da demanda de material recebida para com a eficiência em que é realizado o processo de separação (triagem); - ausência de um local destinado ao armazenamento das bags ${ }^{4}$ já separadas e prontas para serem vendidas; - há também a separação de matérias que não possuem quase nenhum valor comercial como eletrônicos que ficam reservados em uma área aberta; - a falta de um local adequado para o despejo do material a ser triado, que na ausência de espaço coberto é depositado a céu aberto, comprometendo o valor final do material ao ser triado e posteriormente vendido; - o rejeito se distribui em um montante numa área aberta à frente do galpão de triagem, sem qualquer vala para que se destine esse material.

\footnotetext{
${ }^{4}$ Saco de ráfia, utilizado para acomodar os produtos separados.
} 
A cooperativa conta (leitura realizada em 11/12/2013) com setenta e dois cooperados que se revezam em turnos de trabalho.

Por dia, são recebidos aproximadamente seis caminhões no período da manhã com material a ser triado, e mais seis no período da tarde, totalizando em doze caminhões por dia. A rota realizada no local se inicia no momento em que o caminhão chega carregado e é pesado na balança, logo em seguida ele passa pelo segundo patamar e desce em direção ao galpão, o caminhão é descarregado dentro do barracão e então retorna pelo lado oposto ao que chega passando novamente pela área da balança. Por dia, são 3 horas de interrupção da triagem pela atividade de deposição de sacos no galpão.

Outra situação inadequada é a qualidade e a quantidade geradas de rejeitos. São processadas cerca de 200 toneladas de material reciclável mensalmente, destas duzentas, vinte toneladas (10\%) são de rejeitos em que, em avalição visual, pode-se estimar que metade é de rejeito mesmo (materiais organicos que vem misturados ao material reciclável) e a outra metade é de recicláveis comercialmente viáveis que chegam contaminados, e acabam por comprometer o valor daqueles que estão em boas condiçoes, e portanto, são descartados e há também aqueles que são recicláveis, mas atualmente não possuem nenhum valor comercial.

FIGURA 6. (a) Material sendo triado diretamente do local de deposição pelos caminhões; (b) Área Social.
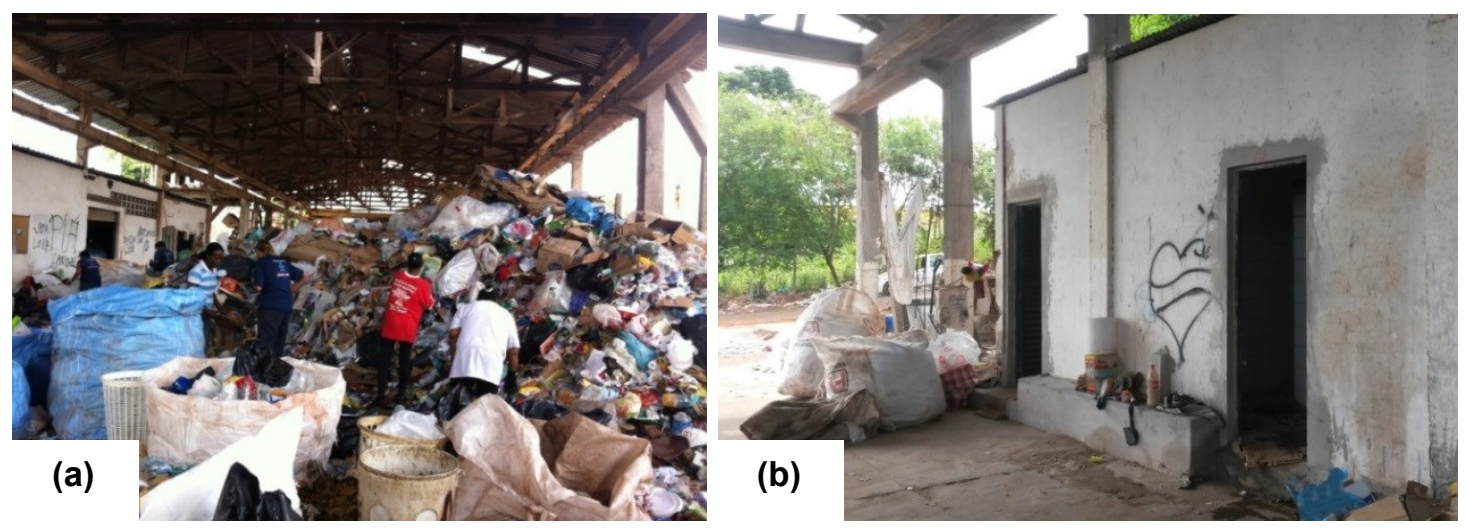

Fonte: PROEX, 2013. 
FIGURA 7. (a) Imagem da fachada do refeitório; (b) Imagem da sala utilizada como vestiário masculino; (c) Imagem da fachada do escritório da área social.
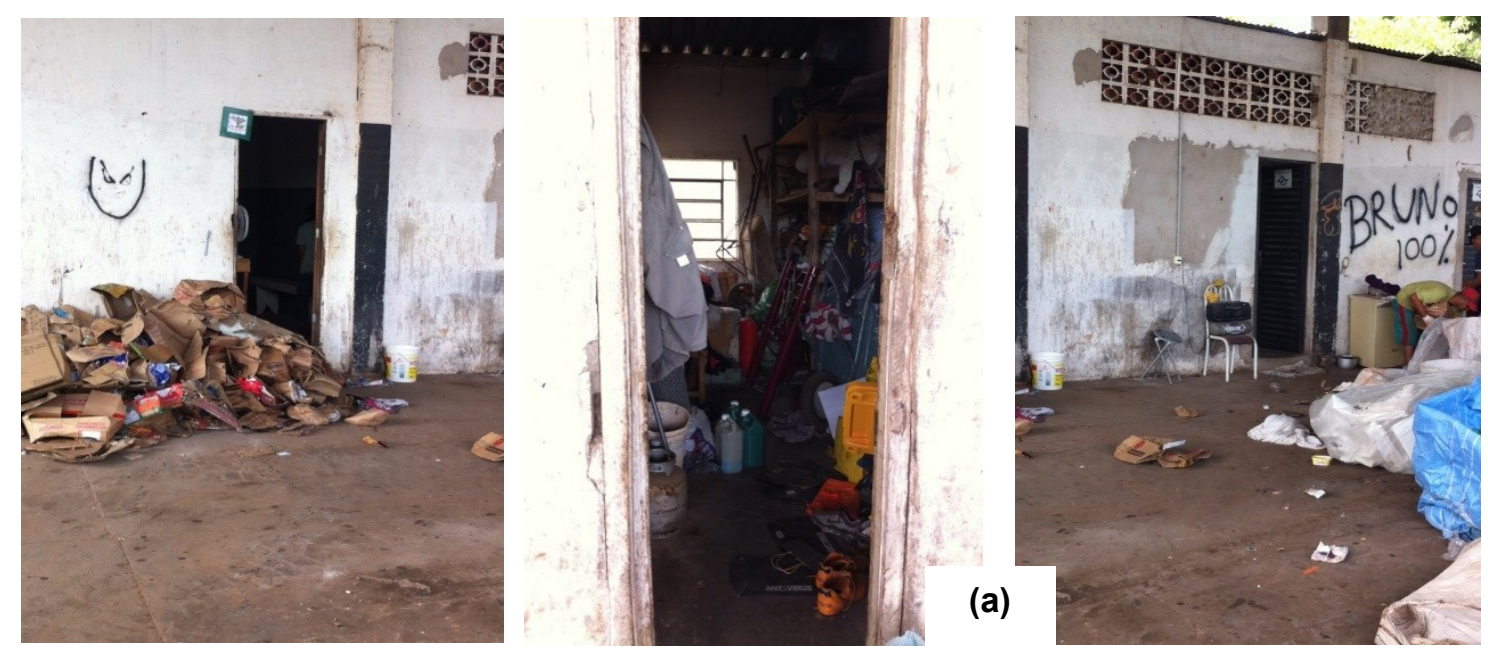

Fon

te:

PR

OE

$\mathrm{X}$

201

(b)

A área social está internamente ao galpão e isso afeta diretamente a funcionalidade e a salubridade do local. Este espaço deveria ser destinado para alimentação, visitas, administração, capacitação e higiene dos cooperados e possíveis visitantes. Porém o fato de se encontrar integrado a àrea de separação do material faz com que seu uso fique comprometido, pois não se encontra em condições adequadas para tais funções.

\subsection{Proposta}

No âmbito da coleta, triagem e comercialização de resíduos recicláveis, o CISSA, Centro de Integração Social e Sustentabilidade Ambiental tem o papel fundamental de organizador espacial das atividades administrativas, das atividades com os resíduos, das atividades relacionadas à educação ambiental e capacitação dos catadores e da comunidade local e também das atividades de suporte à outras fontes geradoras de renda e trabalho.

A proposta para a CoopPrudente está representada pela planta a seguir e demais detalhes. Aproveitou-se o galpão existente, organizou-se o fluxo atual de atividades de recebimento e triagem. Atualmente não há prensas e a venda é direta 
nos bags. Assim, foi proposta a construção de duas edificações adicionais e separadas, destinadas, respectivamente, ao Centro Social e ao Centro de Processamento.

FIGURA 8 - Proposta de Implantação do CISSA-COOPPRUDENTE.

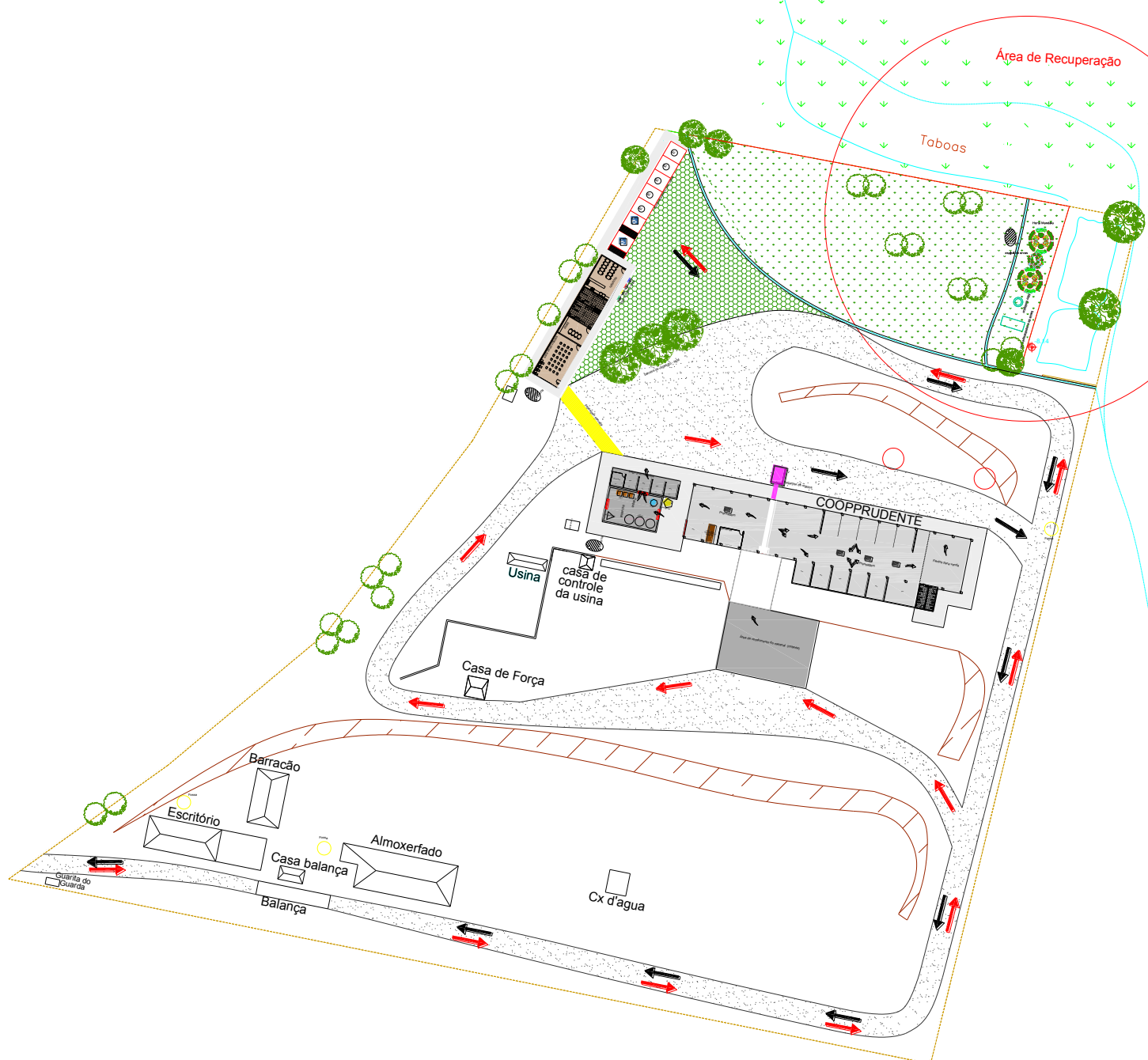

Fonte: PROEX, 2013.

O Centro Social aloca as salas de atividades educacionais, vestiários, banheiros, cozinha, refeitório e sala administrativa. O Centro de Processamento se destina às atividades de trituração de PET, de vidro, ou qualquer pós-processamento 
que agregue valor ao produto triado para a venda. Em termos construtivos, foi indicado, através do projeto e de um memorial descritivo, o uso de tecnologias de construção sustentáveis (materiais e técnicas eficientes e de baixo impacto ambiental), além da reutilização das águas pluviais, o tratamento do esgoto sanitário.

FIGURA 9 - Elevações e Cortes do CISSA-COOPPRUDENTE.
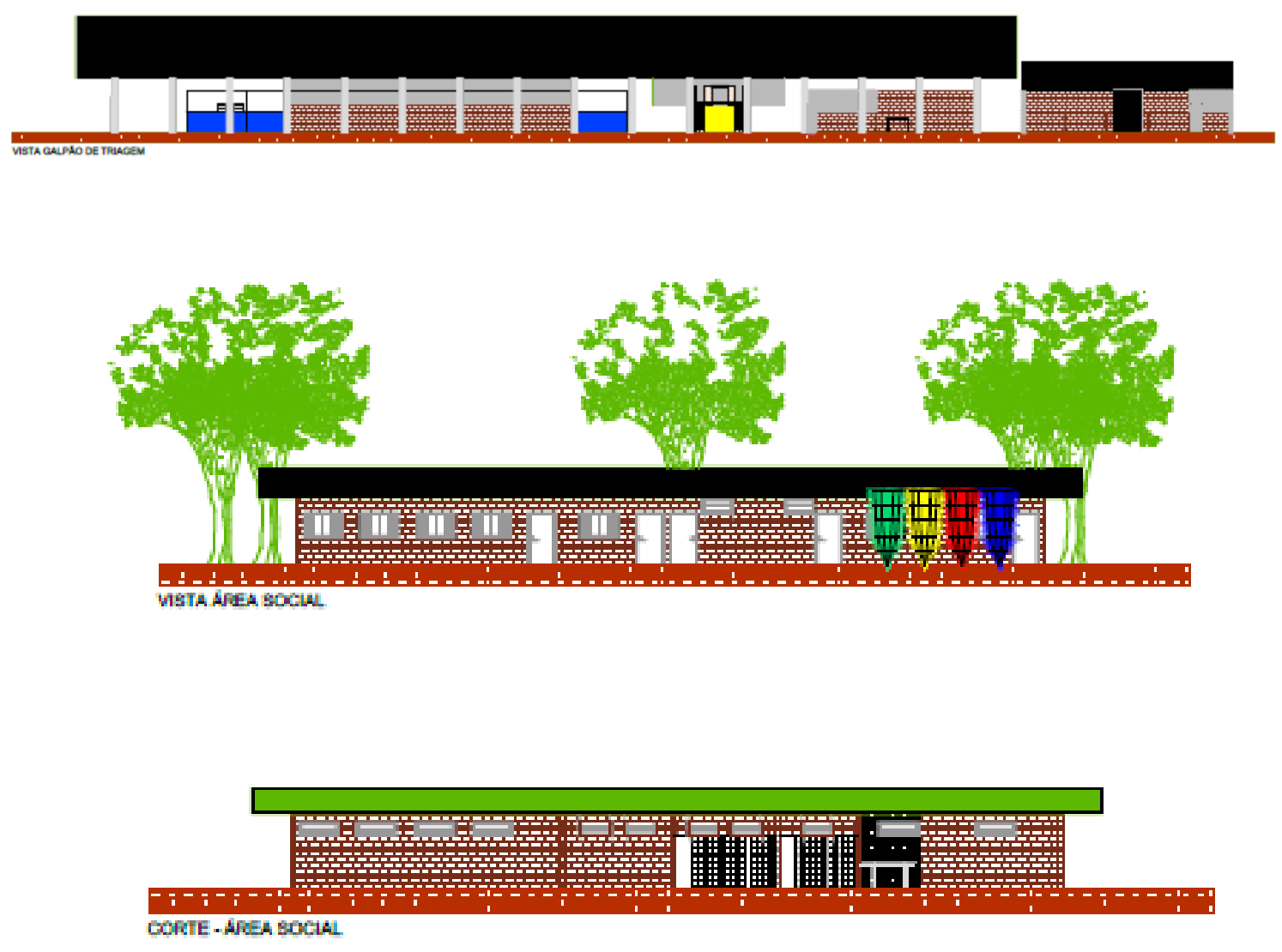

Fonte: PROEX, 2013.

Os resultados do trabalho foram doados à empresa Prudenco em janeiro de 2014 para apreciação e futura implementação. 


\section{CONCLUSÃO}

Conclui-se que há uma extensa área capaz de receber tais atividades de recebimento, triagem, processamento e comercialização de material reciclado. Se planejado, reorganizados e equipados, tais espaços, poderiam processar o dobro ou o triplo do atual volume recebido.

O CISSA é uma resposta às atuais condições precárias de trabalho da atividade de triagem de resíduos recicláveis, ao ineficiente saneamento ambiental praticado pelas gestões municipais e às incoerentes soluções logísticas e construtivas que vem sendo praticadas neste âmbito.

Propõe-se que o Centro de Integração Social e Sustentabilidade Ambiental seja uma edificação (ou conjunto de edificações) de baixo consumo de matéria prima não renovável na sua produção, produza pouco ou nenhum resíduo na sua construção, consuma pouca energia elétrica e água potável na sua operação, tenha ambientes com alta qualidade ambiental e funcionalidade, gere pouco resíduo na sua operação e ainda trate e aproveite parte significativa deles e cause baixo impacto quando sua vida útil extinguir.

\section{REFERÊNCIAS}

BRASIL, 2010. LEI No 12.305, DE 2 DE AGOSTO DE 2010. Institui a Política Nacional de Resíduos Sólidos; altera a Lei no 9.605, de 12 de fevereiro de 1998; e dá outras providências.

PROEX/UNESP - FCT. GERENCIAMENTO DE RESÍDUOS SÓLIDOS URBANOS, ORGANIZAÇÃO DE CATADORES DE MATERIAIS RECICLÁVEIS E EDUCAÇÃO AMBIENTAL. Relatório Final do Projeto de Extensão Universitária, 2013. 